Article

\title{
Tuning the Pore Geometry of Ordered Mesoporous Carbons for Enhanced Adsorption of Bisphenol-A
}

\author{
Wannes Libbrecht ${ }^{1,2,3}$, Koen Vandaele ${ }^{3,4}$, Klaartje De Buysser ${ }^{4}$, An Verberckmoes ${ }^{1}$, \\ Joris W. Thybaut ${ }^{2}$, Hilde Poelman ${ }^{2}$, Jeriffa De Clercq ${ }^{1, *}$ and Pascal Van Der Voort ${ }^{3}$ \\ 1 Industrial Catalysis and Adsorption Technology (INCAT),
}

Department of Industrial Technology and Construction, Faculty of Engineering and Architecture,

Ghent University, Valentin Vaerwyckweg 1, Ghent 9000, Belgium;

E-Mails: Wannes.Libbrecht@ugent.be (W.L.); An.Verberckmoes@ugent.be (A.V.)

2 Laboratory for Chemical Technology, Faculty of Engineering and Architecture, Ghent University,

Technologiepark 914, Ghent 9052, Belgium; E-Mails: Joris.Thybaut@ugent.be (J.W.T.);

Hilde.Poelman@ugent.be (H.P.)

3 Center for Ordered Materials, Organometallics and Catalysis (COMOC),

Department of Inorganic and Physical Chemistry, Ghent University, Krijgslaan 281-S3,

Ghent 9000, Belgium; E-Mails: Koen.Vandaele@ugent.be (K.V.);

Pascal.Vandervoort@ugent.be (P.V.D.V.)

4 Sol-gel Centre for Research on Inorganic Powders and Thin films Synthesis (SCRiPTS),

Department of Inorganic and Physical Chemistry, Ghent University, Krijgslaan 281-S3,

Ghent 9000, Belgium; E-Mail: Klaartje.Debuysser@ugent.be

* Author to whom correspondence should be addressed; E-Mail: Jeriffa.Declercq@ugent.be;

Tel.: +32-92424238.

Academic Editor: Rafael Luque

Received: 25 February 2015 / Accepted: 31 March 2015 / Published: 10 April 2015

\begin{abstract}
Mesoporous carbons were synthesized via both soft and hard template methods and compared to a commercial powder activated carbon (PAC) for the adsorption ability of bisphenol-A (BPA) from an aqueous solution. The commercial PAC had a BET-surface of $1027 \mathrm{~m}^{2} / \mathrm{g}$ with fine pores of $3 \mathrm{~nm}$ and less. The hard templated carbon (CMK-3) material had an even higher BET-surface of $1420 \mathrm{~m}^{2} / \mathrm{g}$ with an average pore size of $4 \mathrm{~nm}$. The soft templated carbon (SMC) reached a BET-surface of $476 \mathrm{~m}^{2} / \mathrm{g}$ and a pore size of $7 \mathrm{~nm}$. The maximum observed adsorption capacity ( $\mathrm{q}_{\max }$ ) of CMK-3 was the highest with $474 \mathrm{mg} / \mathrm{g}$, compared to $290 \mathrm{mg} / \mathrm{g}$ for PAC and $154 \mathrm{mg} / \mathrm{g}$ for SMC. The difference in adsorption
\end{abstract}


capacities was attributed to the specific surface area and hydrophobicity of the adsorbent. The microporous PAC showed the slowest adsorption, while the ordered mesopores of SMC and CMK-3 enhanced the BPA diffusion into the adsorbent. This difference in adsorption kinetics is caused by the increase in pore diameter. However, CMK-3 with an open geometry consisting of interlinked nanorods allows for even faster intraparticle diffusion.

Keywords: ordered mesoporous carbons; hard template; soft template; adsorption; BPA

\section{Introduction}

Porous carbon materials are important in many areas of modern science and technology, with a wide variety of applications, such as catalyst support, electrode material and adsorbents for gas and liquid purification [1]. The popularity of these materials can be attributed to their high specific area, large pore volume, chemical inertness and good mechanical stability [2,3]. Activated carbon (AC) is the most commonly applied carbon material for adsorption due to its low production cost and the possibility for large scale processing. Major disadvantages are the disordered structure, limitation of pore size to micropores $(<2 \mathrm{~nm})$ and irregular pore size distribution. The micropores could limit the mass transfer [4], or decrease pore accessibility for larger adsorbates. Further developments in the field of chromatography, Li-based batteries, electrodes and adsorption demand for materials with increased pore sizes and a controlled pore size distribution $[5,6]$.

The first hard templated ordered mesoporous that were synthesized, used MCM-48 mesoporous silica molecular sieves as template. The resulting replicated mesoporous carbon CMK-1 exhibited porous structures consisting of two disconnected interwoven three-dimensional pore systems [7]. In a similar manner, a well-defined hexagonally ordered mesoporous carbon denoted CMK-3, was synthesized by using SBA-15 mesoporous silica as template [8]. Next to sucrose solution, as in the original paper [9], also furfuryl alcohol or other carbon precursors such as glucose, xylose, acenaphthene, indene, etc. were impregnated in the silica template via the incipient wetness technique $[3,10,11]$. Therefore, an amount of precursor solution equal to the total pore volume of the template is added. It is believed that the whole solution infiltrated the pores through capillary action. The carbon precursor was typically polymerized by means of a sulfuric acid catalyst and subsequently carbonized under inert conditions. The silica template can be removed either under basic conditions or by means of HF. Unfortunately, in all of the above-mentioned methods, the incipient wetness technique was unsuccessful to fill the pores uniformly due to the difficulty to homogenize a powder. Also pore blocking occurs upon subsequent impregnations of a precursor solution via the wet impregnation method. In order to obtain a high surface area, it is important that no carbon precursor is deposited outside the template because this would lead to external carbon upon calcination.

Soft templated synthesis of ordered mesoporous materials by self-assembly of tri-block copolymer surfactants and carbon precursor was pioneered by Dai et al., Nishiyama et al. and Zhao et al. [12-15]. Phenol or resorcinol is polymerized with formaldehyde around the micelles of e.g. pluronic F127 or P123. These amphiphilic surfactants create micelles that adopt tailored symmetries and interact with the carbon precursor. Via an acid or base catalyzed mechanism the precursor reacts into a phenolic resin [2]. 
The mesostructure formation is aided by the evaporation induced self-assembly (EISA) at acid or neutral $\mathrm{pH}$ conditions or by the self-assembly under weakly basic conditions in a hydrothermal synthesis procedure [16]. An increased stability is obtained due to the continuous framework with rigid walls [17]. Variation of morphology is possible by applying different reaction parameters or synthesis mechanisms [1]. Unlike the hard template method, a well-defined symmetry is difficult to achieve for the soft template method. However, under very specific reaction conditions, Zhao et al. [18] synthesized a range of (FDU-type) materials with well-defined symmetries.

To investigate the adsorption capabilities of both mesoporous carbons: soft templated (SMC) and hard templated (CMK-3), BPA was chosen as an adsorbate because it is classified as an endocrine disrupting chemical, putting human health and its reproductive system at risk, which makes the efficient removal of BPA a priority [19-22]. The adsorption of BPA on activated carbon has been studied intensively [23-25], and maximum adsorption capacities ( $\mathrm{q}_{\max }$ ) from $30 \mathrm{mg} / \mathrm{g}$ [25] to as high as $430 \mathrm{mg} / \mathrm{g}$ are reported [23]. Important differences are the natural source of the AC, varying from wood [25], to coconut shell [24], to charcoal [23], which will affect the specific surface area as well as surface chemistry by altering the amount of acidic oxygen-containing groups. More recently developed advanced carbon materials tested for BPA adsorption were carbon nanotubes [26] and graphene sheets [27] with a qmax of, respectively, $70 \mathrm{mg} / \mathrm{g}$ and $182 \mathrm{mg} / \mathrm{g}$.

The objective of this study was to understand the effect of different material characteristics, such as specific surface area, hydrophobicity, pore diameter and pore geometry on the adsorption of BPA by comparing both types of mesoporous carbons and commercial activated carbon. A simple method for the synthesis of CMK-3 was developed. In this synthesis toluene is added after furfuryl alcohol impregnation to avoid the deposit of excess furfuryl alcohol onto the external surface of the silica template. This resulted in a high surface area CMK-3 with well-ordered symmetry. Also, a quick and easy acid-catalyzed EISA synthesis for soft template mesoporous carbon is provided [28]. The synthesis can be performed at room temperature without any $\mathrm{pH}$ adjustments or purification steps and results in a well-ordered 2D hexagonal mesoporous material.

\section{Results and Discussion}

\subsection{Characterization of the Adsorbents}

The $\mathrm{N}_{2}$-isotherms of the three adsorbents are shown in Figure 1. The BET surface areas, pore volumes, and density functional theory (DFT) pore diameters are listed in Table 1. The PAC surface area and pore volume are $1027 \mathrm{~m}^{2} / \mathrm{g}$ and $0.50 \mathrm{~cm}^{3} / \mathrm{g}$, respectively, containing mainly micropores, confirmed by the type I isotherm, with a pore diameter below $2.5 \mathrm{~nm}$. The CMK-3 material has a very high surface area $\left(1420 \mathrm{~m}^{2} / \mathrm{g}\right)$ and pore volume $\left(1.14 \mathrm{~cm}^{3} / \mathrm{g}\right)$ with a pore diameter of $4 \mathrm{~nm}$. The soft templated mesoporous carbon (SMC) has a surface area of $476 \mathrm{~m}^{2} / \mathrm{g}$, pore volume of $0.49 \mathrm{~cm}^{3} / \mathrm{g}$ and an average pore diameter of $7.2 \mathrm{~nm}$. Both mesoporous materials exhibit a type IV isotherm with a type H1 hysteresis indicating uniform cylindrical pores. The capillary condensation of CMK-3 occurs at a lower $\mathrm{p} / \mathrm{p}_{0}$ than SMC indicating a smaller pore size as seen in Figure 1. 


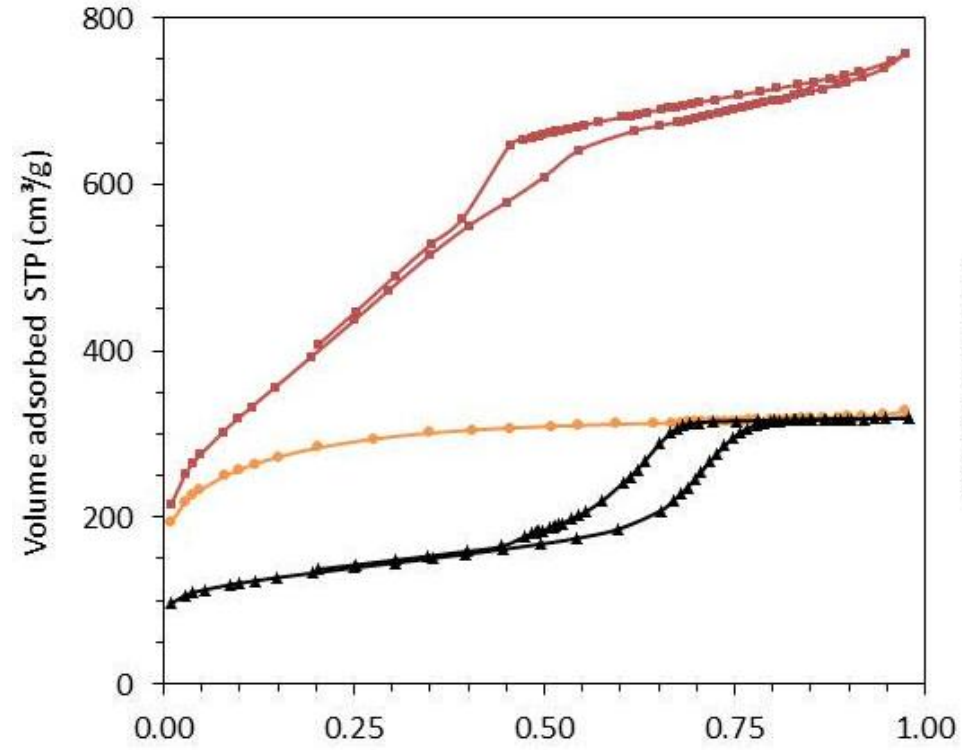

(a) Relative pressure $\left(\mathrm{p} / \mathrm{p}_{0}\right)$

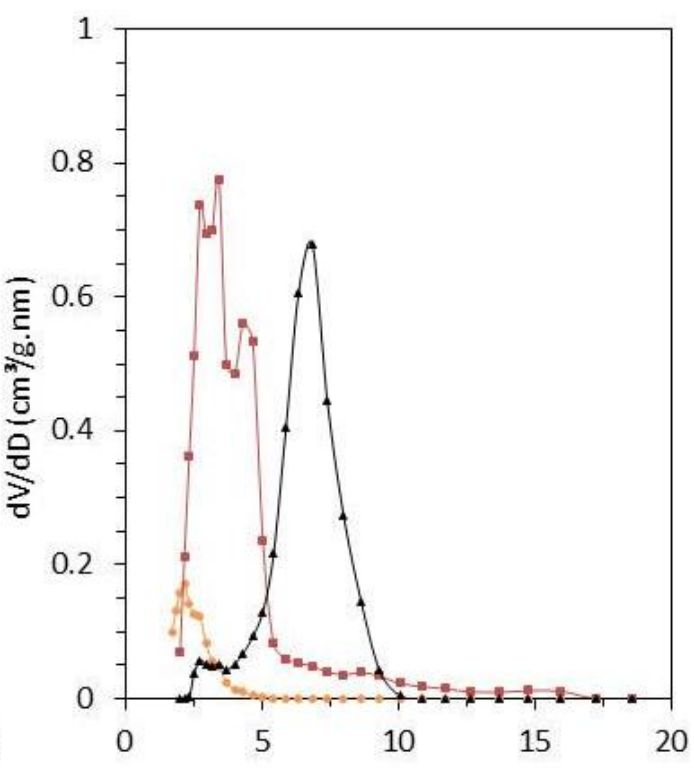

(b) Pore size (nm)

Figure 1. Nitrogen sorption isotherms (a) and their corresponding pore size distributions

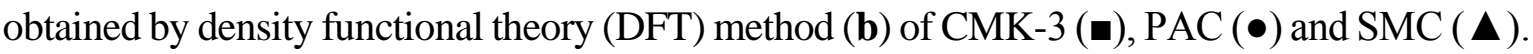

Table 1. Structural properties of the materials.

\begin{tabular}{|c|c|c|c|c|c|}
\hline Material & $\begin{array}{c}\text { Specific Surface Area } \\
\qquad\left(\mathrm{m}^{2} / \mathrm{g}\right)\end{array}$ & $\begin{array}{l}\text { Pore Volume } \\
\qquad\left(\mathrm{cm}^{3} / \mathrm{g}\right)\end{array}$ & $\begin{array}{c}\text { Pore diameter D } \\
(\mathbf{n m})\end{array}$ & $\begin{array}{c}\text { Unit cell parameter }^{\text {a }} \\
\qquad \mathbf{a}_{0}(\mathbf{n m})\end{array}$ & $\begin{array}{c}\text { Wall thickness }{ }^{\text {a }} \\
\text { (nm) }\end{array}$ \\
\hline PAC & 1027 & 0.50 & $<3$ & - & - \\
\hline CMK-3 & 1420 & 1.14 & 4.0 & 9.6 & 5.6 \\
\hline SMC & 476 & 0.49 & 7.0 & 11.6 & 4.6 \\
\hline
\end{tabular}

Note: ${ }^{a}$ Based on the hexagonal porous structure, the unit cell sizes were calculated by using the formula $\mathrm{a}=2 \mathrm{~d}(100) / \sqrt{3}$ and pore wall thicknesses were calculated from the formula of $\mathrm{h}=\mathrm{a}-\mathrm{D}$, with a and $\mathrm{D}$ the unit cell parameter and pore diameter, respectively.

Powder X-ray diffraction patterns of the synthesized mesoporous carbons are shown in Figure 2. The SMC shows a well resolved (100) reflection at $2 \theta=0.88^{\circ}$ and high order reflection (110) and (200) of the highly ordered 2D hexagonal symmetry. The CMK-3 material also shows a (100) reflection at $2 \theta=1.06^{\circ}$ with higher order reflections indicating the $2 \mathrm{D}$ hexagonal symmetry. The cell parameter (a0) of SMC and CMK-3 were calculated from d(100), d(110) and d(200) and were $11.6 \mathrm{~nm}$ and $9.6 \mathrm{~nm}$, respectively. The successful synthesis of highly ordered hard and soft template mesoporous carbons was validated by the TEM images of Figure 3. Both pore size diameters and structures are in agreement with nitrogen sorption isotherms and XRD patterns.

The elemental analysis (Table 2) shows a 93 wt \% carbon for both mesoporous carbons. These materials consist mainly of pure carbon walls with a small amount of oxygen containing functional groups. The PAC on the other hand has about $86 \mathrm{wt} \%$ carbon and a higher amount of oxygen (Table 2), which is due to the steam activation process during production. The increasing carbon or decreasing oxygen amount indicates a more hydrophobic surface of the mesoporous carbons [23,29]. Because the interactions between BPA and the carbon material are mainly $\pi-\pi$ interactions, BPA is expected to adsorb more readily on hydrophobic adsorbents [27,28] 


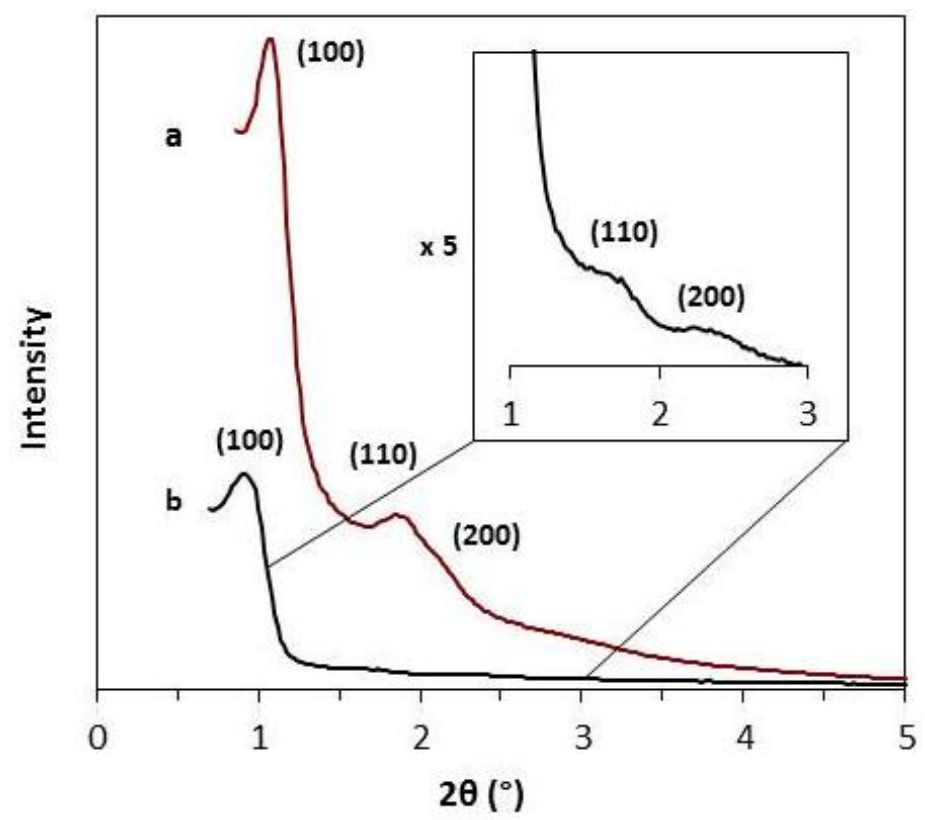

Figure 2. Powder X-ray diffraction patterns of CMK-3 (a) and SMC (b).

(a)

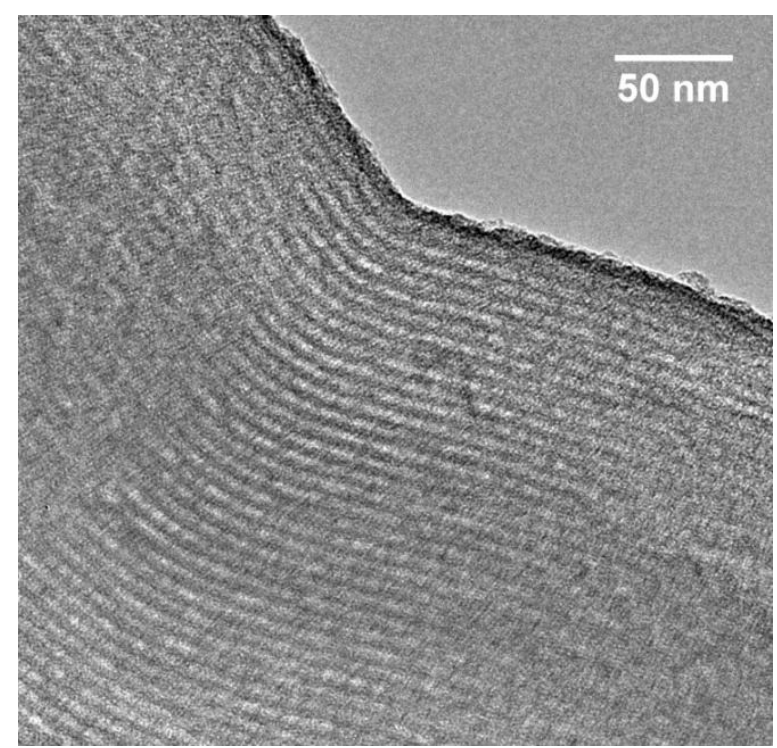

(b)

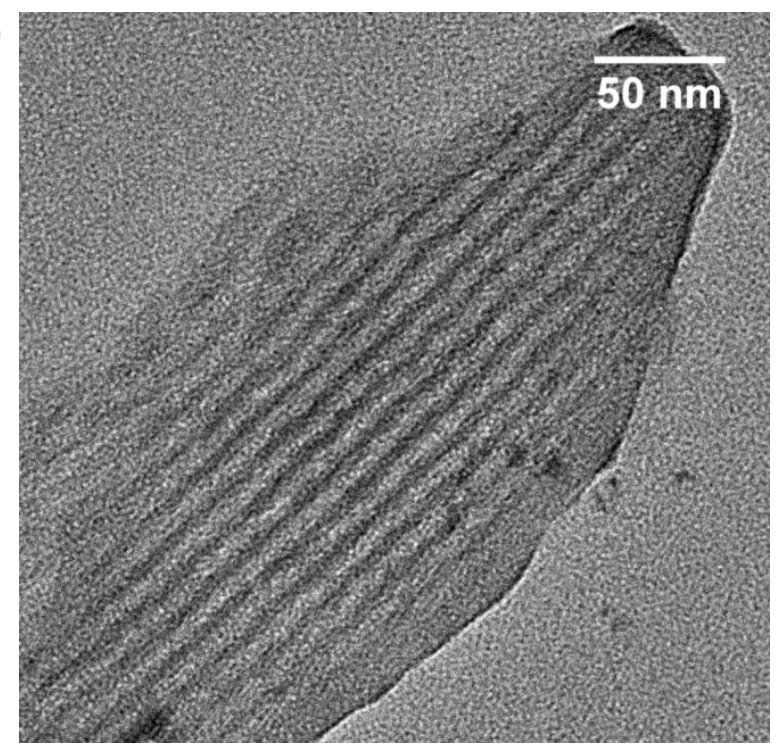

Figure 3. Transmission electron microscope (TEM) images of CMK-3 (a) and SMC (b).

Table 2. Elemental composition of the three carbon adsorbents.

\begin{tabular}{ccccc}
\hline \multirow{2}{*}{ Material } & \multicolumn{4}{c}{ Elemental analysis [wt \%] } \\
\cline { 2 - 5 } & $\mathbf{C}$ & $\mathbf{H}$ & $\mathbf{N}$ & $\mathbf{O}$ \\
\hline PAC & 85.90 & 0.45 & 0.29 & 13.36 \\
CMK-3 & 93.33 & 0.68 & 0.07 & 5.92 \\
SMC & 93.93 & 0.50 & 0.08 & 5.49 \\
\hline
\end{tabular}

\subsection{Adsorption Isotherms}

Figure 4 shows the adsorption isotherms of CMK-3, SMC and PAC. CMK-3 has the highest adsorption capacity, followed by PAC and SMC. The experimental data were fitted with Langmuir and 
Freundlich isotherms (Table 3). The isotherms of the mesoporous materials are better described by the Freundlich model (Equation (3)), while the experimental PAC-data are better described by the Langmuir model (Equation (2)). This implies multilayer adsorption could occur within the wide pores of the mesoporous materials, while for PAC, mainly consisting of micropores, adsorption will be limited to a monolayer. The observed maximum adsorption capacities are $474 \mathrm{mg} / \mathrm{g}, 290 \mathrm{mg} / \mathrm{g}$, and $154 \mathrm{mg} / \mathrm{g}$ for, respectively, CMK-3, PAC and SMC. To the best of our knowledge the adsorption capacity of $474 \mathrm{mg} / \mathrm{g}$ for CMK-3 is the highest reported. BPA adsorption from water on a carbon adsorbent is mainly influenced by specific surface area and hydrophobicity of the surface due to $\pi-\pi$ interactions between BPA and the adsorbate $[23,27,28]$. As the specific surface area increases from SMC, over PAC to CMK-3 (Table 1), the adsorbed BPA amount increases. To compare the materials without the effect of specific surface area, the observed maximum adsorption capacities are converted to the number of adsorbed molecules per $\mathrm{nm}^{2}$ (Table 3). The more hydrophobic mesoporous carbons, CMK-3 and SMC, with about 94 wt $\%$ carbon, have a higher amount of molecules adsorbed per $\mathrm{nm}^{2}: 0.88$ molecules $/ \mathrm{nm}^{2}$ and 0.86 molecules $/ \mathrm{nm}^{2}$ compared to the less hydrophobic PAC $\left(0.75\right.$ molecules per $\left.\mathrm{nm}^{2}\right)$.

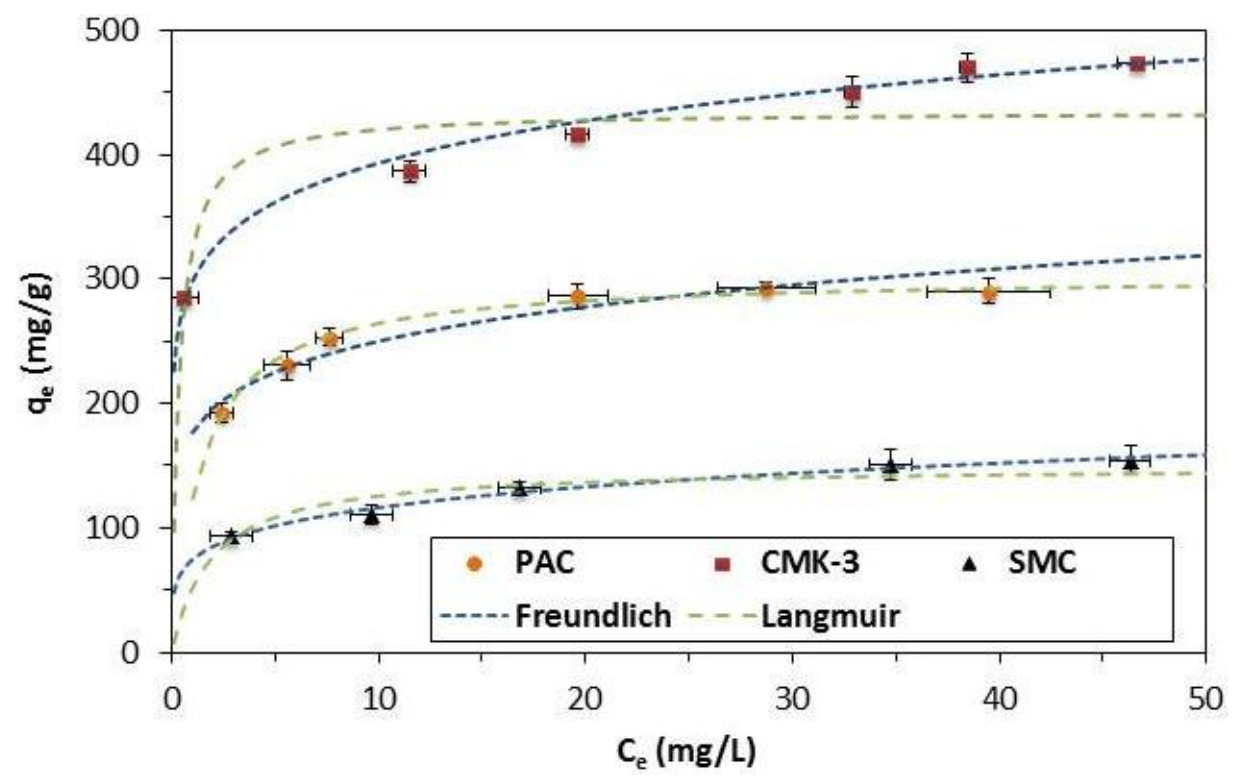

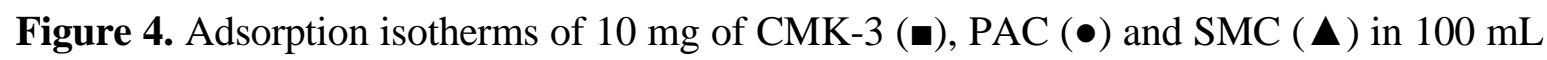
of bisphenol-A (BPA)-solution, experimental data were fitted with the Langmuir and Freundlich model, the error bars represent the standard deviation of the triplicate measurements.

Table 3. The observed maximum adsorption capacity in $\mathrm{mg} / \mathrm{g}$ and converted to molecules per $\mathrm{nm}^{2}$, parameters describing the adsorption isotherms of BPA on PAC, CMK-3 and SMC modeled by Langmuir and Freundlich.

\begin{tabular}{|c|c|c|c|c|c|c|c|c|}
\hline \multirow[b]{2}{*}{ Material } & \multicolumn{2}{|c|}{ Experimental } & \multicolumn{3}{|c|}{ Langmuir } & \multicolumn{3}{|c|}{ Freundlich } \\
\hline & $\begin{array}{c}\mathbf{q}_{\max } \\
(\mathrm{mg} / \mathrm{g})\end{array}$ & $\begin{array}{c}\text { Adsorbed BPA } \\
\text { (molecules/nm²) }\end{array}$ & $\begin{array}{c}\text { qmax } \\
(\mathrm{mg} / \mathrm{g}) \\
\end{array}$ & $\begin{array}{c}\mathrm{K}_{\mathrm{L}} \\
(\mathrm{L} / \mathbf{m g})\end{array}$ & $\mathbf{R}^{2}$ & $1 / n$ & $\begin{array}{c}K_{F} \\
\left(\mathrm{mg} / \mathrm{g}(\mathrm{L} / \mathrm{mg})^{1 / \mathbf{n}}\right)\end{array}$ & $\mathbf{R}^{2}$ \\
\hline PAC & 290 & 0.75 & 307 & 0.64 & 0.98 & 0.14 & 181 & 0.93 \\
\hline CMK-3 & 474 & 0.88 & 447 & 2.81 & 0.82 & 0.12 & 296 & 0.99 \\
\hline SMC & 154 & 0.86 & 156 & 0.40 & 0.87 & 0.19 & 74 & 0.98 \\
\hline
\end{tabular}




\subsection{Adsorption Kinetics}

The adsorption kinetics of BPA on PAC, CMK-3 and SMC for the smallest particle size $(62-88 \mu \mathrm{m})$ are shown in Figure 5, where the adsorption capacity $\mathrm{q}$, normalized to the equilibrium adsorption capacity $\mathrm{q}_{\mathrm{e}}$ is given as function of time. This allows comparison of the three materials with different equilibrium adsorption capacities $\left(\mathrm{q}_{\mathrm{e}}\right)$ and therefore a different driving force for BPA removal. It is clear that adsorption on CMK-3 is the fastest, reaching equilibrium after $20 \mathrm{~min}$. SMC reaches equilibrium at about $60 \mathrm{~min}$, while PAC has not yet reached equilibrium after $90 \mathrm{~min}$. It is noteworthy that SMC adsorbs faster than PAC, although SMC has a lower equilibrium adsorption capacity than PAC: $154 \mathrm{mg} / \mathrm{g}$ versus $290 \mathrm{mg} / \mathrm{g}$. The experimental data were fitted with the pseudo-first-order, pseudo-second-order and Weber-Morris kinetic model (Table 4). The kinetics for all three materials were best described by the pseudo-second-order kinetic model. The adsorption kinetics of organic pollutants on carbon materials has often been described with pseudo-second-order kinetics [4,23,24,27]. Based on the Weber-Morris kinetic model, a plot of $\mathrm{q}_{\mathrm{t}}$ versus $\mathrm{t}^{1 / 2}$ should be linear if intraparticle diffusion was involved in the adsorption process. Moreover, if the straight line passes through the origin, intraparticle diffusion is the rate-determining step. Only the PAC data showed a straight line, with an extrapolation passing almost through the origin. This suggests that intraparticle diffusion contributes to the adsorption kinetics of PAC.

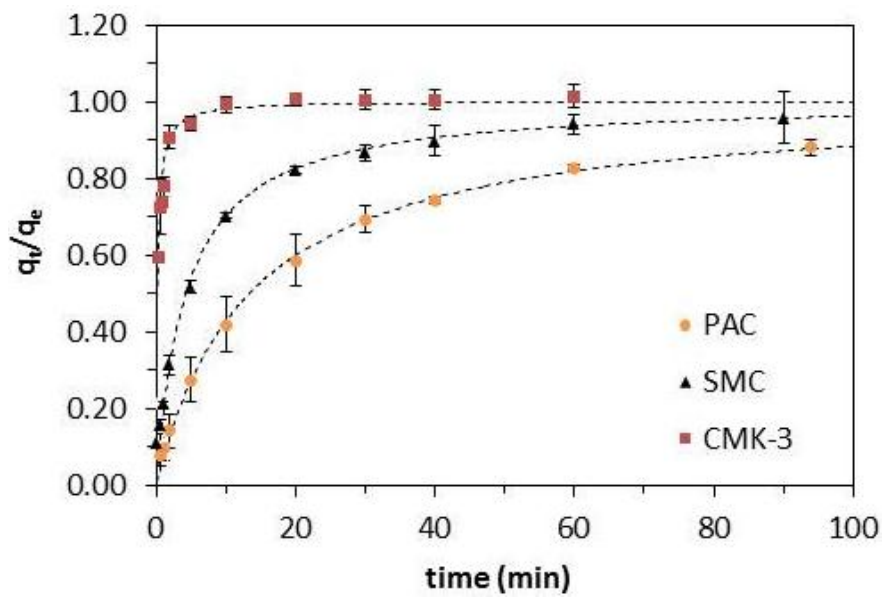

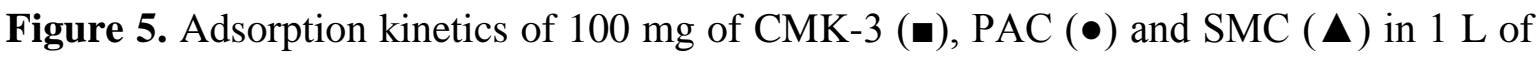
$60 \mathrm{mg} / \mathrm{L} \mathrm{BPA}$-solution, particle size is between 62 and $88 \mu \mathrm{m}$, the error bars represent the standard deviation of the triplicate measurements, the dashed lines represent the pseudo-second-order kinetic model descriptions.

Table 4. Parameters of the pseudo-first-order, pseudo-second-order and Weber-Morris kinetic models for adsorption of BPA on PAC, CMK-3 and SMC.

\begin{tabular}{|c|c|c|c|c|c|c|c|c|c|c|c|}
\hline \multirow[b]{2}{*}{ Material } & \multirow[b]{2}{*}{$\begin{array}{c}q_{\mathrm{e}}(\exp ) \\
(\mathrm{mg} / \mathrm{g})\end{array}$} & \multicolumn{3}{|c|}{ Pseudo-first-order model } & \multicolumn{4}{|c|}{ Pseudo-second-order model } & \multicolumn{3}{|c|}{ Weber-Morris } \\
\hline & & $\begin{array}{c}\text { qe (calc) } \\
(\mathrm{mg} / \mathrm{g})\end{array}$ & $\begin{array}{c}k_{1} \\
(1 / \mathrm{min})\end{array}$ & $\mathbf{R}^{2}$ & $\begin{array}{c}\text { qe (calc) } \\
(\mathrm{mg} / \mathrm{g})\end{array}$ & $\begin{array}{c}k_{2} \\
(g /(m g \cdot \min )\end{array}$ & $\begin{array}{c}\mathbf{t}_{1 / 2} \\
(\mathrm{~min})\end{array}$ & $\mathbf{R}^{2}$ & $\begin{array}{c}k_{d} \\
(\min \cdot g /(m g))\end{array}$ & $\begin{array}{c}\mathrm{C} \\
(\mathrm{mg} / \mathrm{g})\end{array}$ & $\mathbf{R}^{2}$ \\
\hline PAC & 277 & 264 & 0.0657 & 0.98 & 315 & 0.00024 & 13.4 & 0.99 & 31.2 & 13.2 & 0.94 \\
\hline CMK-3 & 295 & 281 & 2.64 & 0.77 & 291 & 0.01647 & 0.208 & 0.96 & 13.7 & 215 & 0.65 \\
\hline SMC & 147 & 137 & 0.0236 & 0.97 & 149 & 0.00157 & 4.27 & 0.99 & 15.0 & 29.6 & 0.86 \\
\hline
\end{tabular}


Although the BPA-molecule with molecular dimensions of $1.068 \mathrm{~nm} \times 0.587 \mathrm{~nm} \times$ $0.383 \mathrm{~nm}[25,27,30,31]$ is able to enter micropores and PAC has been reported as a successful adsorbent in multiple studies [23,24,32], the observed adsorption kinetics in Figure 5 show that the larger pores of mesoporous carbons increase the efficiency of these materials beyond that of PAC. This is consistent with literature reporting that the use of mesoporous materials as adsorbent has proven to increase adsorption rate and efficiencies [4,29,33]. The BPA molecule diffuses more readily in the larger mesopores and is adsorbed faster. The difference in rate between CMK-3 and SMC can be attributed to the pore geometry. SMC consists of 2D hexagonal arranged long pores, while CMK-3 consists of interconnected nanorods (Figure 6). This open pore system of CMK-3 allows for a faster intraparticle diffusion and removal rate of the adsorbate, as observed in Figure 5.

(a)

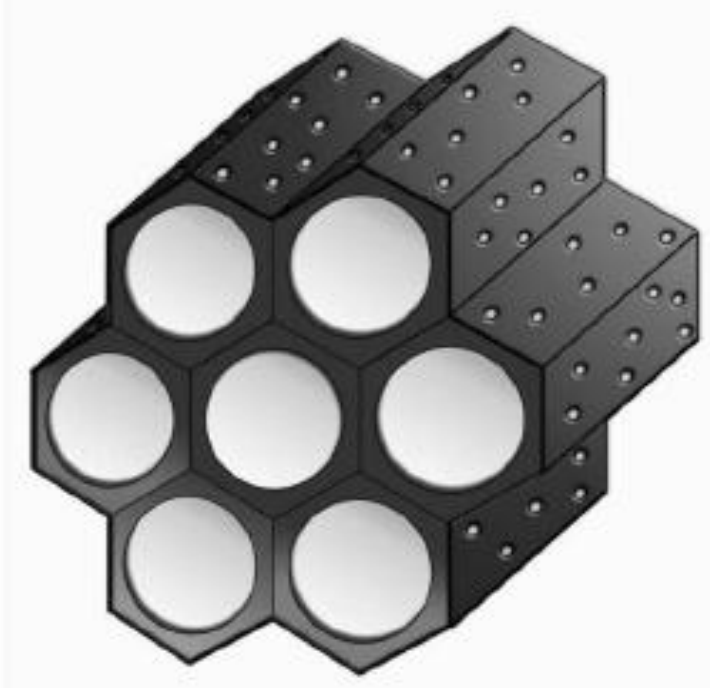

(b)

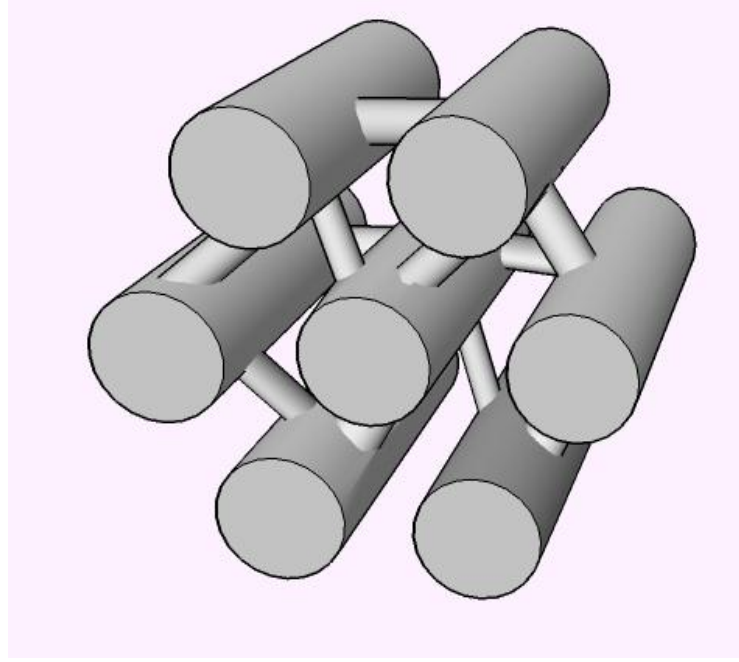

Figure 6. (a) Schematic representation of $2 \mathrm{D}$ hexagonal mesoporous structure of SMC and (b) the interconnected nanorod structure of CMK-3.

The effect of particle size on the adsorption kinetics was further investigated for SMC and PAC (Figure 7). With increasing particle size, the removal rate of BPA on PAC is considerably lowered. The irregular structured micropores of the PAC particles clearly indicate that intraparticle diffusion is the rate-controlling step. This was also confirmed by fitting the PAC data of Figure 7 to the Weber-Morris kinetic model (Table 5). The removal rate of BPA on SMC is higher than that of PAC, because the mesopores allow a better diffusion through the material. Remarkably, in the SMC with larger pores and a well-ordered structure, intraparticle diffusion also controls the removal rate (Figure 7). This could be explained by the pore structure: in larger particles, the average distance travelled by diffusion in the long 2D hexagonal pores will be longer. Fitting the SMC data of Figure 7 to the Weber-Morris kinetic model confirmed the contribution of intraparticle diffusion in larger SMC particles (Table 5). 

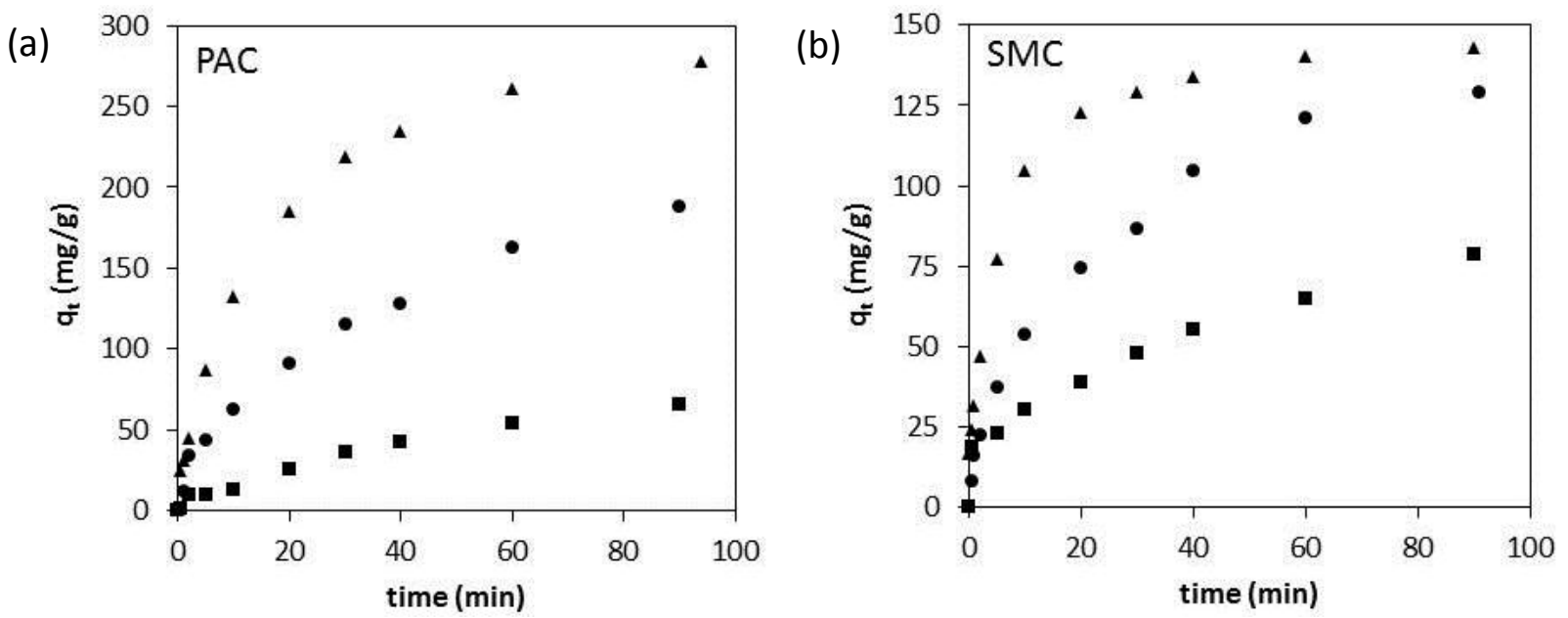

Figure 7. Effect of particle size $62-88 \mu \mathrm{m}(\mathbf{\Delta}), 177-250 \mu \mathrm{m}(\bullet)$ and 510-700 $\mu \mathrm{m}(\mathbf{\square})$, on the adsorption kinetics of $100 \mathrm{mg}$ of PAC (a) or SMC (b) in $1 \mathrm{~L}$ of $60 \mathrm{mg} / \mathrm{L}$ BPA-solution.

Table 5. Parameters of the Weber-Morris kinetic model for adsorption of BPA on PAC and SMC with different particle sizes.

\begin{tabular}{cccccccc}
\hline $\mathbf{P A C}$ & $\mathbf{k}_{\mathbf{d}}(\mathbf{m i n} \cdot \mathbf{g} / \mathbf{m g})$ & $\mathbf{C}$ & $\mathbf{R}^{\mathbf{2}}$ & $\mathbf{S M C}$ & $\mathbf{k}_{\mathbf{d}}(\mathbf{m i n} \cdot \mathbf{g} / \mathbf{m g})$ & $\mathbf{C}$ & $\mathbf{R}^{\mathbf{2}}$ \\
\hline $62-88 \mu \mathrm{m}$ & 31.2 & 13.2 & 0.94 & $62-88 \mu \mathrm{m}$ & 15.0 & 29.6 & 0.86 \\
$177-250 \mu \mathrm{m}$ & 20.9 & -3.93 & 0.99 & $177-250 \mu \mathrm{m}$ & 13.5 & 6.10 & 0.97 \\
$510-700 \mu \mathrm{m}$ & 7.62 & -6.68 & 0.98 & $510-700 \mu \mathrm{m}$ & 8.33 & 2.60 & 0.99 \\
\hline
\end{tabular}

\section{Experimental Section}

\subsection{Synthesis of Ordered Mesoporous Carbons}

A commercial activated carbon was supplied by Desotec (Roeselare, Belgium). For the hard templated mesoporous carbon CMK-3 synthesis, $2.5 \mathrm{~g}$ of the template SBA-15 was impregnated with $10 \mathrm{~mL}$ solution of $25 \mathrm{v} \%$ furfuryl alcohol ( $\geq 98 \%$ purity, Sigma-Aldrich, Steinheim, Germany) in toluene ( $\geq 99.5 \%$ purity, Sigma-Aldrich). To catalyze the reaction, $200 \mu \mathrm{L}$ of $0.1 \mathrm{~mol} / \mathrm{L} \mathrm{H}_{2} \mathrm{SO}_{4}$ (Sigma-Aldrich) is added. The solution was refluxed for $36 \mathrm{~h}$ at $90{ }^{\circ} \mathrm{C}$ while stirring vigorously. Next, the impregnated silica is filtered and washed 3 times with toluene and dried at $150{ }^{\circ} \mathrm{C}$ for $5 \mathrm{~h}$ in a Nabertherm muffle oven. The composite material is carbonized at $1100{ }^{\circ} \mathrm{C}$ for $1 \mathrm{~h}$ in a Carbolite tubular furnace under $\mathrm{Ar}-5 \% \mathrm{H}_{2}$ atmosphere with a heating rate of $2{ }^{\circ} \mathrm{C} / \mathrm{min}$. The silica is leached out by stirring with a $10 \% \mathrm{HF}$ solution (Sigma-Aldrich) for a minimum of $6 \mathrm{~h}$. Less than $3 \mathrm{wt} \% \mathrm{SiO}_{2}$ was detected in the CMK-3 by X-ray fluorescence (Rigaku NEX CG, Tokyo, Japan).

The soft templated mesoporous carbon synthesis was based on Wang et al. [34]. Resorcinol (2.2 g; Sigma-Aldrich) and F127 (2.2 g; Sigma-Aldrich) were mixed with $9 \mathrm{~mL}$ ethanol ( $\geq 99.8 \%$ purity VWR) and $9 \mathrm{~mL} \mathrm{HCl}(3 \mathrm{~mol} / \mathrm{L})$ and stirring for $15 \mathrm{~min}$ at room temperature. Then, formaldehyde (2.6 g) (Formalin, $37 \mathrm{wt} \%$ formaldehyde in water; Sigma-Aldrich) was added and the solution was stirred again for $15 \mathrm{~min}$. The solution was subsequently poured onto a glass plate to evaporate the ethanol at room temperature for $6 \mathrm{~h}$. Next, the film was scraped from the glass plate and put into a petri-dish in a Nabertherm muffle oven where the material was cured at $60{ }^{\circ} \mathrm{C}$ for $12 \mathrm{~h}$. The cured resin was calcined 
and carbonized under $\mathrm{N}_{2}$-flow in a Thermolite tubular furnace with a heating rate of $1{ }^{\circ} \mathrm{C} / \mathrm{min}$. In the first heating step to $350{ }^{\circ} \mathrm{C}$ for $2 \mathrm{~h}$, the surfactant was removed. The second heating step to $800{ }^{\circ} \mathrm{C}$ for $3 \mathrm{~h}$ carbonized the resorcinol/formaldehyde resin.

\subsection{Characterization}

Powder X-ray diffraction (PXRD) patterns of the adsorbents were collected on a Thermo Scientific ARL X'Tra diffractometer, operated at $40 \mathrm{kV}, 40 \mathrm{~mA}$ using $\mathrm{Cu} \mathrm{K} \alpha$ radiation. The PXRD patterns were measured from $0.6^{\circ}$ to $5^{\circ}$ with a step size of $0.02^{\circ}$. Nitrogen gas sorption experiments were conducted at $-196{ }^{\circ} \mathrm{C}$ using a Micromeritics Tristar 3000. Samples were vacuum-dried at $120{ }^{\circ} \mathrm{C}$ overnight prior to analysis. The pore size distribution (PSD) was calculated with the DFT method using a carbon kernel (Microactive software, Micromeritics). Total pore volume $\mathrm{V}_{\text {tot }}$ was calculated as the amount of nitrogen adsorbed at a relative pressure of 0.95 . The total surface area SBET was determined using the Brunauer-Emmett-Teller (BET) method. Elemental analysis was performed with a CHNS-O analyzer Thermo Scientific Flash 2000, with a TCD detector, using the Eager Experience software. Images of the ordered mesopores were obtained by a TEM (Jeol JEM Cs-corrected 2200FS, Peabody, MA, USA, operating at $200 \mathrm{kV}$ ).

\subsection{Adsorption Tests}

Kinetic experiments were performed by adding $100 \mathrm{mg}$ of adsorbent with a particle size of 62 to $88 \mu \mathrm{m}$ to $1 \mathrm{~L}$ of $30 \mathrm{mg} / \mathrm{L} \mathrm{BPA} \mathrm{(>99 \%} \mathrm{purity;} \mathrm{Sigma-Aldrich)} \mathrm{solution.} \mathrm{These} \mathrm{aqueous} \mathrm{BPA} \mathrm{solutions} \mathrm{were}$ stirred at room temperature at $600 \mathrm{rpm} .5 \mathrm{~mL}$ samples were taken at different time intervals up to $100 \mathrm{~min}$, filtered through a $0.45 \mu \mathrm{m}$ PET syringe filter and the BPA concentrations were analyzed with a Thermo scientific Evolution 60 UV/VIS spectrophotometer at a wavelength of $275 \mathrm{~nm}$. In order to ascertain that the obtained data are free from external diffusion limitations across the solid-liquid interface, preliminary kinetic experiments at different agitation speeds (300,600 and $900 \mathrm{rpm})$ confirmed that external mass transfer resistance is negligible from an agitation speed of $600 \mathrm{rpm}$ for all three adsorbents (results not shown) [35].

The internal mass-transfer effect was studied by using different adsorbent particle sizes for PAC and SMC. Both materials were crushed and sieved in three different particle sizes $(62-88 \mu \mathrm{m}, 177-250 \mu \mathrm{m}$ and $510-700 \mu \mathrm{m}$ ) with a Mini-sieve micro sieve set (Sigma-Aldrich). Because CMK-3 is a very fine powder, only the smallest particle size fraction was available. Pelletizing of CMK-3 gave larger particle sizes, however upon mixing in solution the particles disintegrated back to the very fine powder.

Isotherm experiments were performed by adding $10 \mathrm{mg}$ of adsorbent to $100 \mathrm{~mL}$ of aqueous BPA solution with different BPA concentrations (ranging from $5 \mathrm{mg} / \mathrm{L}$ to $70 \mathrm{mg} / \mathrm{L}$ ). Subsequently, the solutions were placed in a thermostatic shaking device (Infors HT, multitron standard) at $25{ }^{\circ} \mathrm{C}$ for $24 \mathrm{~h}$. Next, the solutions were filtered through a $0.45 \mu \mathrm{m}$ PET syringe filter and analyzed for its BPA concentrations.

Both kinetic and isotherm experiments were performed in triplicate. 
The adsorption capacity at time $\mathrm{t}$ was calculated according to Equation (1):

$$
q_{t}=\frac{\left(C_{0}-C_{t}\right) V}{m}
$$

with $q_{t}(\mathrm{mg} / \mathrm{g})$ the adsorption capacity at time $t ; C_{0}(\mathrm{mg} / \mathrm{L})$ and $C_{t}(\mathrm{mg} / \mathrm{L})$ the initial concentration and concentration at time $t ; m(\mathrm{~g})$ the adsorbent mass and $V(\mathrm{~L})$ the solution volume.

The isotherm data were fitted to the well-known Langmuir (Equation (2)) and Freundlich (Equation (3)) isotherms:

$$
\begin{gathered}
q_{e}=\frac{\mathrm{q}_{\max } \mathrm{K}_{\mathrm{L}} C_{e}}{1+\mathrm{K}_{\mathrm{L}} C_{e}} \\
q_{e}=\mathrm{K}_{\mathrm{F}} C_{e}^{1 / \mathrm{n}}
\end{gathered}
$$

with $\mathrm{q}_{\max }(\mathrm{mg} / \mathrm{g})$ the maximum adsorption capacity; $C_{e}(\mathrm{mg} / \mathrm{L})$ the equilibrium concentration; $\mathrm{K}_{\mathrm{L}}(\mathrm{L} / \mathrm{mg})$ the Langmuir constant; $\mathrm{K}_{\mathrm{F}}\left(\mathrm{mg} / \mathrm{g} \cdot(\mathrm{L} / \mathrm{mg})^{1 / \mathrm{n}}\right)$ and $\mathrm{n}(-)$ the Freundlich constants.

The kinetic data were fitted to the pseudo-first-order (Equation (4)), the pseudo-second-order (Equation (4)), and the Weber-Morris kinetic model (Equation (6)):

$$
\begin{gathered}
q_{t}=q_{e}\left(1-e^{-\mathrm{k}_{1} t}\right) \\
q_{t}=\frac{q_{e} t}{\frac{1}{\mathrm{k}_{2} q_{e}}+t} \\
q_{t}=\mathrm{k}_{\mathrm{d}} t^{1 / 2}+\mathrm{C}
\end{gathered}
$$

with $\mathrm{k}_{1}(1 / \mathrm{min})$ the pseudo-first-order rate constant; $\mathrm{k}_{2}(\mathrm{~g} /(\mathrm{mg} \cdot \mathrm{min}))$ the pseudo-second-order rate constant; $\mathrm{kd}(\mathrm{min} \cdot \mathrm{g} / \mathrm{mg})$ the intraparticle diffusion rate constant and $\mathrm{C}(\mathrm{mg} / \mathrm{g})$ the intercept.

\section{Conclusions}

Commercial activated carbon and synthesized hard and soft templated mesoporous carbons were fully characterized and tested for their BPA adsorption capacity and kinetics. Both mesoporous materials showed a well-ordered 2D hexagonal structure, SMC consists of cylindrical pores with a size of $7.0 \mathrm{~nm}$ while CMK-3 has an interconnected nanorod structure with an average pore size of $4.0 \mathrm{~nm}$. The observed maximum adsorption capacity increased with the specific surface area of the material, CMK-3 showed a very high adsorption capacity of $474 \mathrm{mg} / \mathrm{g}$, and outperforms PAC with an adsorption capacity of $290 \mathrm{mg} / \mathrm{g}$. When calculating the number of molecules adsorbed per $\mathrm{nm}^{2}$, both mesoporous materials, i.e., SMC and CMK-3, performed better than PAC. This difference was attributed to the more hydrophobic nature of SMC and CMK-3 compared to PAC. The adsorption kinetics showed a clear advantage of mesoporous materials over PAC. The BPA removal rate of CMK-3 was fastest followed by SMC and PAC. For both SMC and PAC the increase in particle size resulted in a slower BPA removal, which shows that the adsorption is controlled by intraparticle diffusion, although this effect was more pronounced for PAC than SMC. In conclusion, mesoporous carbons are promising adsorbents for the removal of BPA, especially CMK-3 with its interconnected nanorod structure and high specific surface area resulting in the highest removal rate as well as adsorption capacity. 


\section{Acknowledgments}

The Research Fund of the University College Ghent and the faculty of Engineering and Architecture of Ghent University and the Fund for Scientific Research-Flanders (FWO), as well as the "Long Term Structural Methusalem Funding by the Flemish Government" are acknowledged for their financial support. The authors want to thank Glenn Pollefeyt (Department of Inorganic and Physical Chemistry, Ghent University) for TEM measurements and Tom Planckaert (Department of Inorganic and Physical Chemistry, Ghent University) for elemental analysis measurements.

\section{Author Contributions}

Optimization of the synthesis of all non-commercial adsorbents was performed by Koen Vandaele and Wannes Libbrecht. Klaartje De Buysser, An Verberckmoes, Hilde Poelman and Pascal Van Der Voort were involved in the thorough characterization of the materials, using the funding and equipment of INCAT, LCT and COMOC. Adsorption studies and interpretation were performed by Wannes Libbrecht, Joris W. Thybaut and Jeriffa De Clercq. All authors contributed to the analysis and interpretation of the results and to the manuscript and have given approval of the final version to be submitted.

\section{Conflicts of Interest}

The authors declare no conflict of interest.

\section{References}

1. Ma, T.-Y.; Liu, L.; Yuan, Z.-Y. Direct synthesis of ordered mesoporous carbons. Chem. Soc. Rev. 2013, 42, 3977-4003.

2. Muylaert, I.; Verberckmoes, A.; de Decker, J.; van der Voort, P. Ordered mesoporous phenolic resins: Highly versatile and ultra stable support materials. Adv. Colloid Interface Sci. 2012, 175, 39-51.

3. Ryoo, R.; Joo, S.H.; Kruk, M.; Jaroniec, M. Ordered mesoporous carbons. Adv. Mater. 2001, 13, 677-681.

4. Sui, Q.; Huang, J.; Liu, Y.; Chang, X.; Ji, G.; Deng, S.; Xie, T.; Yu, G. Rapid removal of bisphenol A on highly ordered mesoporous carbon. J. Environ. Sci. 2011, 23, 177-182.

5. Wu, Z.; Zhao, D. Ordered mesoporous materials as adsorbents. Chem. Commun. 2011, 47, 3332-3338.

6. Liu, L.; Deng, Q.-F.; Liu, Y.-P.; Ren, T.-Z.; Yuan, Z.-Y. $\mathrm{HNO}_{3}$-activated mesoporous carbon catalyst for direct dehydrogenation of propane to propylene. Catal. Commun. 2011, 16, 81-85.

7. Kruk, M.; Jaroniec, M.; Ryoo, R.; Joo, S.H. Characterization of ordered mesoporous carbons synthesized using MCM-48 silicas as templates. J. Phys. Chem. B 2000, 104, 7960-7968.

8. Jun, S.; Joo, S.H.; Ryoo, R.; Kruk, M.; Jaroniec, M.; Liu, Z.; Ohsuna, T.; Terasaki, O. Synthesis of new, nanoporous carbon with hexagonally ordered mesostructure. J. Am. Chem. Soc. 2000, 122, 10712-10713. 
9. Ryoo, R.; Joo, S.H.; Jun, S. Synthesis of highly ordered carbon molecular sieves via template-mediated structural transformation. J. Phys. Chem. B 1999, 103, 7743-7746.

10. Kim, T.-W.; Park, I.-S.; Ryoo, R. A synthetic route to ordered mesoporous carbon materials with graphitic pore walls. Angew. Chem. Int. Ed. Engl. 2003, 42, 4375-4379.

11. Gierszal, K.P.; Jaroniec, M.; Kim, T.-W.; Kim, J.; Ryoo, R. High temperature treatment of ordered mesoporous carbons prepared by using various carbon precursors and ordered mesoporous silica templates. New J. Chem. 2008, 32, 981-993.

12. Liang, C.; Hong, K.; Guiochon, G.A.; Mays, J.W.; Dai, S. Synthesis of a large-scale highly ordered porous carbon film by self-assembly of block copolymers. Angew. Chem. 2004, 116, 5909-5913.

13. Liang, C.; Dai, S. Synthesis of mesoporous carbon materials via enhanced hydrogen-bonding interaction. J. Am. Chem. Soc. 2006, 128, 5316-5317.

14. Tanaka, S.; Nishiyama, N.; Egashira, Y.; Ueyama, K. Synthesis of ordered mesoporous carbons with channel structure from an organic-organic nanocomposite. Chem. Commun. 2005, 16, 2125-2127.

15. Zhang, F.; Meng, Y.; Gu, D.; Yan, Y.; Yu, C.; Tu, B.; Zhao, D. A facile aqueous route to synthesize highly ordered mesoporous polymers and carbon frameworks with $I a 3 d$ bicontinuous cubic structure. J. Am. Chem. Soc. 2005, 127, 13508-13509.

16. Schlienger, S.; Graff, A.-L.; Celzard, A.; Parmentier, J. Direct synthesis of ordered mesoporous polymer and carbon materials by a biosourced precursor. Green Chem. 2012, 14, 313-316.

17. Muylaert, I.; Borgers, M.; Bruneel, E.; Schaubroeck, J.; Verpoort, F.; van der Voort, P. Ultra stable ordered mesoporous phenol/formaldehyde polymers as a heterogeneous support for vanadium oxide. Chem. Commun. 2008, 37, 4475-4477.

18. Meng, Y.; Gu, D.; Zhang, F.; Shi, Y.; Cheng, L.; Feng, D.; Wu, Z.; Chen, Z.; Wan, Y.; Stein, A.; et al. A family of highly ordered mesoporous polymer resin and carbon structures from organic-organic self-assembly. Chem. Mater. 2006, 18, 4447-4464.

19. Chen, M.; Ike, M.; Fujita, M. Acute toxicity, mutagenicity, and estrogenicity of bisphenol-A and other bisphenols. Environ. Toxicol. 2002, 17, 80-86.

20. Nakamura, D.; Yanagiba, Y.; Duan, Z.; Ito, Y.; Okamura, A.; Asaeda, N.; Tagawa, Y.; Li, C.; Taya, K.; Zhang, S.Y.; et al. Bisphenol A may cause testosterone reduction by adversely affecting both testis and pituitary systems similar to estradiol. Toxicol. Lett. 2010, 194, 16-25.

21. Belfroid, A.; van Velzen, M.; van der Horst, B.; Vethaak, D. Occurrence of bisphenol A in surface water and uptake in fish: evaluation of field measurements. Chemosphere 2002, 49, 97-103.

22. Cousins, I.T.; Staples, C.A.; Klecka, G.M.; Mackay, D. A multimedia assessment of the environmental fate of bisphenol A. Hum. Ecol. Risk Assess. 2002, 8, 1107-1135.

23. Liu, G.; Ma, J.; Li, X.; Qin, Q. Adsorption of bisphenol A from aqueous solution onto activated carbons with different modification treatments. J. Hazard. Mater. 2009, 164, 1275-1280.

24. Tsai, W.-T.; Lai, C.-W.; Su, T.-Y. Adsorption of bisphenol-A from aqueous solution onto minerals and carbon adsorbents. J. Hazard. Mater. 2006, 134, 169-175.

25. Nakanishi, A.; Tamai, M.; Kawasaki, N.; Nakamura, T.; Tanada, S. Adsorption characteristics of bisphenol A onto carbonaceous materials produced from wood chips as organic waste. J. Colloid Interface Sci. 2002, 252, 393-396. 
26. Kuo, C.-Y. Comparison with as-grown and microwave modified carbon nanotubes to removal aqueous bisphenol A. Desalination 2009, 249, 976-982.

27. Xu, J.; Wang, L.; Zhu, Y. Decontamination of bisphenol A from aqueous solution by graphene adsorption. Langmuir 2012, 28, 8418-8425.

28. Libbrecht, W.; Deruyck, F.; Poelman, H.; Verberckmoes, A.; Thybaut, J.; de Clercq, J.; van der Voort, P. Optimization of soft templated mesoporous carbon synthesis using Definitive Screening Design. Chem. Eng. J. 2015, 259, 126-134.

29. Liu, F.; Xu, Z.; Wan, H.; Wan, Y.; Zheng, S.; Zhu, D. Enhanced adsorption of humic acids on ordered mesoporous carbon compared with microporous activated carbon. Environ. Toxicol. Chem. 2011, 30, 793-800.

30. Agenson, K. Retention of a wide variety of organic pollutants by different nanofiltration/reverse osmosis membranes: Controlling parameters of process. J. Memb. Sci. 2003, 225, 91-103.

31. Nghiem, L.D.; Vogel, D.; Khan, S. Characterising humic acid fouling of nanofiltration membranes using bisphenol A as a molecular indicator. Water Res. 2008, 42, 4049-4058.

32. Soni, H.; Padmaja, P. Palm shell based activated carbon for removal of bisphenol A: An equilibrium, kinetic and thermodynamic study. J. Porous Mater. 2014, 21, 275-284.

33. Konicki, W.; Cendrowski, K.; Chen, X.; Mijowska, E. Application of hollow mesoporous carbon nanospheres as an high effective adsorbent for the fast removal of acid dyes from aqueous solutions. Chem. Eng. J. 2013, 228, 824-833.

34. Wang, X.; Liang, C.; Dai, S. Facile synthesis of ordered mesoporous carbons with high thermal stability by self-assembly of resorcinol-formaldehyde and block copolymers under highly acidic conditions. Langmuir 2008, 24, 7500-7505.

35. Leyva-ramos, R. Role of pore volume and surface diffusion in the adsorption of aromatic compounds on activated carbon. Adsorption 2013, 19, 945-957.

(C) 2015 by the authors; licensee MDPI, Basel, Switzerland. This article is an open access article distributed under the terms and conditions of the Creative Commons Attribution license (http://creativecommons.org/licenses/by/4.0/). 